\title{
Treatment of Distillery Spentwash by Electrocoagulation
}

\author{
V. Khandegar and Anil K. Saroh
}

\begin{abstract}
Effluent from distilleries, known as spent wash, leads to extensive soil and water pollution. Removal of pollutants and color from distillery effluent is becoming increasingly important from environmental and aesthetic point of view. Effluent from distilleries contains certain recalcitrant compounds. In the present work effort were made to reduce chemical oxygen demand (COD) from distillery effluent by electrocoagulation. The maximum COD removal efficiency of $98 \%$ was obtained at solution $\mathrm{pH}$ of 7.2 with a current density $17.9 \mathrm{~mA} / \mathrm{cm}^{2}$ for electrolysis duration of $3 \mathrm{~h}$. Further experiments were performed using aluminum sulphate as chemical coagulant to compare the COD removal efficiencies obtained by electrocoagulation and chemical coagulation.
\end{abstract}

Index Terms-Spentwash, electrocoagulation, coagulation, aluminum.

\section{INTRODUCTION}

Distillery spentwash is the effluent basically generated by fermentation of sugar cane molasses to produce alcohol. For every litre of alcohol, maximum 8-15 litres of spentwash are generated. India is the fourth largest producer of ethanol in the world and the second largest in Asia [1]. Alcohol distilleries are rated as one of the 17 most polluting industries and generate large volumes of high strength wastewater that is of serious environmental concern. Spent wash is characterized by extremely high chemical oxygen demand (COD) (80,000-120,000 $\mathrm{mg} / \mathrm{L})$, biochemical oxygen demand (BOD) (40,000-50,000 mg/L), acidic $\mathrm{pH}$, strong odor, nutrients in the form of nitrogen (1660-4200 $\mathrm{mg} / \mathrm{L}$ ), phosphorus (225-3038 mg/L), potassium (9600$17,475 \mathrm{mg} / \mathrm{L}$ ) can lead to eutrophication of water bodies and dark brown color hinders photosynthesis by blocking sunlight and is therefore deleterious to aquatic life.

Various physical, chemical and biological techniques are used for the treatment of distillery spent wash before its discharge to the aqueous ecosystem [2], [3]. In biological treatment anaerobic treatment attractive in comparison to direct aerobic treatment due to high organic content of molasses present in spent wash [4].

Bio-methanation is employed as a primary treatment step in majority of the distillery units. In this treatment, effluent is usually subjected to anaerobic digestion for removing organic matter and producing biogas which is used as a fuel substitute to produce steam for the fermentation process [5], [6]. The effluent after bio-methanation still contains substantial amount of organic matter and does not remove the color. These difficulties are solved by application of

Manuscript received May 14, 2013; revised July 17, 2013.

Anil K. Saroha is with Dept. of Chemical Engineering, Indian Institute of Technology, Delhi Hauz Khas, New Delhi-110016, India (e-mail: aksaroha@chemical.iitd.ac.in). other treatment like reverse osmosis or ultrafiltration/nanofiltration technique. This technique provides colorless water form spentwash, which can be reused in molasses fermentation. The concentrated spentwash after reverse osmosis treatment has very high BOD and COD and it is difficult to compost or incinerate to achieve zero liquid discharge as desired by pollution control authorities. Hence, there is a need to find out a techno economically feasible treatment method [7]. Many researchers have used electrocoagulation method for the treatment of wastewater. The electrocoagulation treatment is an emerging technology used for the destruction of recalcitrant organics from different synthetic wastewaters [8]-[10] as well as industrial wastewaters [11], [12]. Electrocoagulation (EC) is a simple and efficient method and has been used for the treatment of many types of wastewaters [2], [5], [7], [13], [14]-[16]. Treatment of distillery spent wash has been reported by various authors and summarized in Table I.

\section{MATERIALS AND Methods}

In the present study, reverse osmosis reject (ROR) is collected from a distillery was characterized for various parameters and the results are shown in Table II. Chemical oxygen demand (COD), a measure of organic strength of the spent wash, was determined by the dichromate method (open reflux, titrimetric method, APHA, 1998) [17]. It can be noticed that the reverse osmosis reject from distillery industry have very high COD content $(52,000 \mathrm{mg} / \mathrm{L})$.

The experiments were conducted in a $500 \mathrm{ml}$ glass beaker in batch mode of operation. Aluminum and iron sheets with dimensions of $150 \mathrm{~mm} \times 32 \mathrm{~mm} \times 1.5 \mathrm{~mm}$ (length $\times$ width $\times$ thickness) were used as electrodes. Experiments were conducted using $\mathrm{Al}-\mathrm{Al}$ and $\mathrm{Fe}-\mathrm{Fe}$ combination of electrodes.

The electrodes were connected in a monopolar connection mode. A direct current source (GWINSTEK, GPS 4303 India, 0-3A, 0- $30 \mathrm{~V}$ ) was used for current supply. The contents in the beaker were agitated by a magnetic stirrer (SPINOT 02, India) to avoid concentration gradients. Each experimental run was performed by charging $300 \mathrm{ml}$ of the sample in the glass beaker. The results were evaluated in terms of COD removal efficiency. Repeated experiments were performed to check the reproducibility of the experimental results and the reproducibility was found to be $\pm 3 \%$.

\section{RESUlTS AND DiscUSSION}

\section{A. Effect of $p H$ of the Solution}

Initially experiments were conducted at original solution $\mathrm{pH} 7.2$. 
TABLE I: ELECTROCOAGULATION USED FOR TREATMENT OF DISTILLERY SPENTWASH

\begin{tabular}{|l|l|l|l|l|l||}
\hline Reference & Current density & Time (min) & pH & Anode-Cathode & COD removal efficiency (\%) \\
\hline Khandegar and Saroha (2012) & $0.817 \mathrm{~A} / \mathrm{cm}^{2}$ & 120 & 3 & $\mathrm{Al}-\mathrm{Al}, \mathrm{Al}-\mathrm{Fe}, \mathrm{Fe}-\mathrm{Fe}$ & $81.3,71.8,52.4$ \\
& & & & & 72.3 \\
\hline Krishna et al. (2010) & $0.03 \mathrm{~A} / \mathrm{cm}^{2}$ & 120 & 3 & $\mathrm{Al}-\mathrm{Al}$ & 37 \\
\hline Prasad and Srivastava (2009) & $14.285 \mathrm{~mA} / \mathrm{cm}^{2}$ & 180 & 5 & $\left(\mathrm{RuO}_{2}\right.$-Ti)-SS & 63.1 \\
\hline Thakur et al. (2009) & $146.75 \mathrm{~A} / \mathrm{m}^{2}$ & 130 & 6.75 & $\mathrm{SS}-\mathrm{SS}$ & 85.2 \\
\hline Manisankar et al. (2004) & $6 \mathrm{~A} / \mathrm{dm}^{2}$ & 180 & $6.9-7.2$ & Graphite-Graphite & \\
\hline
\end{tabular}

TABLE II: CHARACTERIZATIONS OF THE EFFLUENT

\begin{tabular}{||l|l||}
\hline Parameter & Value \\
\hline $\mathrm{pH}$ & 7.2 \\
\hline Chemical oxygen demand (mg/L) & 52000 \\
\hline Color & Dark brown \\
\hline Total dissolved solids (mg/L) & 82395 \\
\hline Conductivity (mS/cm) & 29.6 \\
\hline Salinity (mg/L) & 30500 \\
\hline
\end{tabular}

The COD removal efficiency $84.6 \%$ and $76.9 \%$ was obtained at initial $\mathrm{pH}$ (7.2), for $\mathrm{Al}-\mathrm{Al}$ and $\mathrm{Fe}-\mathrm{Fe}$ electrodes respectively. Further experiments were conducted at different $\mathrm{pH}$ of the $\mathrm{ROR}(4,5,6)$ by aluminum and iron electrodes to study the effect of $\mathrm{pH}$ on the EC process and the results are shown in Fig. 1(a) and Fig. 1(b) respectively. The electrolysis was performed for $3 \mathrm{~h}$ with a constant current density of $14.7 \mathrm{~mA} / \mathrm{cm}^{2}(0.41 \mathrm{~A})$, agitation speed was kept constant at $500 \mathrm{rpm}$ and the spacing between the electrodes was $3 \mathrm{~cm}$. It can be noticed from Fig. 1(a) and Fig. 1(b) that $\mathrm{pH}$ of the spent wash had a significant effect on the COD removal efficiency. For $\mathrm{pH}<6$, the protons in the solution get reduced to $\mathrm{H}_{2}$ and thus, the proportion of hydroxide ion produced is less and as a result less COD removal efficiency obtained at low $\mathrm{pH}$ [13]. The COD removal efficiency of Al-Al electrodes is higher as compared to $\mathrm{Fe}-\mathrm{Fe}$ electrodes because the $\mathrm{Fe}$ (II) ions generated during the EC process from iron electrodes has high solubility at acidic conditions and are easily oxidized into Fe (III) [5], [18]. Since Fe (III) is difficult to settle, it leads to the decrease in COD removal efficiency for iron electrodes. Further, Al-Al combination of electrodes was found to be most suitable for the treatment of reverse osmosis reject effluent.

\section{B. Effect of Current Density}

Experiments were performed at different current densities of $12.5,14.7$ and $17.9 \mathrm{~mA} / \mathrm{cm}^{2}$ to study the effect of current density on COD reduction. The experiments were conducted for $3 \mathrm{~h}$ keeping the electrode distance $(3 \mathrm{~cm})$, agitation speed (500 rpm) and the effluent $\mathrm{pH}(7.2)$ and the results are shown in Fig. 2(a) and Fig. 2(b). It can be noticed that the maximum COD removal efficiency (Al-Al $98 \%$ and $\mathrm{Fe}-\mathrm{Fe}$ $84.5 \%)$ was obtained at an applied current density of $17.9 \mathrm{~mA} / \mathrm{cm}^{2}$ in $3 \mathrm{~h}$ electrolysis time.

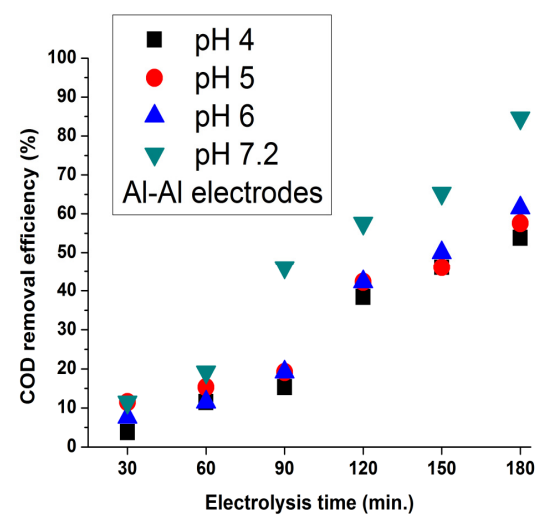

Fig. 1. (a) Effect of $\mathrm{pH}$ on the COD removal efficiency, electrodes Al-Al, current density $14.7 \mathrm{~mA} / \mathrm{cm}^{2}(10 \mathrm{~V})$, electrode spacing $3 \mathrm{~cm}$, agitation speed $500 \mathrm{rpm}$, Initial COD $52000 \mathrm{mg} / \mathrm{L}$.

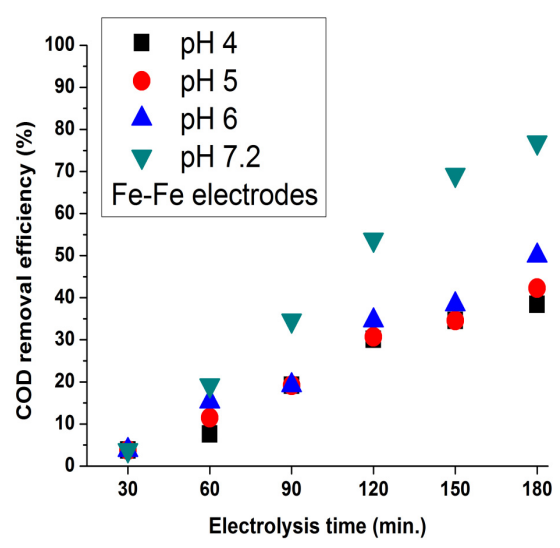

Fig. 1. (b) Effect of $\mathrm{pH}$ on the COD removal efficiency, electrodes Fe-Fe, current density $14.7 \mathrm{~mA} / \mathrm{cm}^{2}(10 \mathrm{~V})$, electrode spacing $3 \mathrm{~cm}$, agitation speed $500 \mathrm{rpm}$, and Initial COD $52000 \mathrm{mg} / \mathrm{L}$.

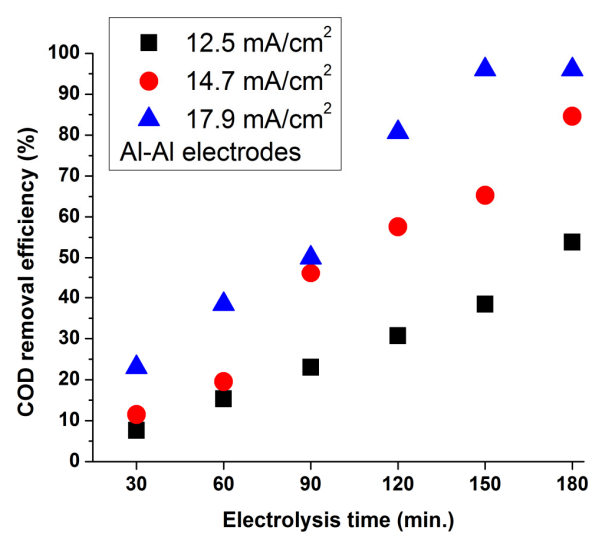

Fig. 2 (a). Effect of current density on the COD removal efficiency, electrodes Al-Al, pH 7.2, electrode spacing $3 \mathrm{~cm}$, agitation speed $500 \mathrm{rpm}$, Initial COD $52000 \mathrm{mg} / \mathrm{L}$ 


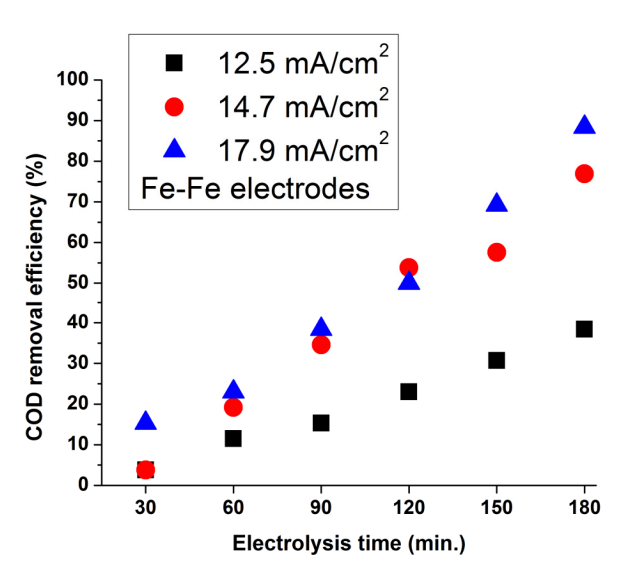

Fig. 2. (b) Effect of current density on the COD removal efficiency, electrodes $\mathrm{Fe}-\mathrm{Fe}, \mathrm{pH} 7.2$, electrode spacing $3 \mathrm{~cm}$, agitation speed $500 \mathrm{rpm}$, and Initial COD $52000 \mathrm{mg} / \mathrm{L}$

The COD removal efficiency was found to increase with an increase in the current density. This is due to the fact that with an increase in the current density, the anode dissolution increases due to the Faradays law. Further, with an increase in the current density, there is an increase in the potential needed for the production of chlorine/hypochlorite leading to increased generation of chlorine/hypochlorite at higher current densities [2], [7].

\section{Cost Estimation}

The operational cost of treatment method is very important criterion for evaluation of the method applicability in industrial use. Electrocoagulation operating cost included mainly cost of energy consumption, cost of the electrode dissolved and the cost of addition of any external chemical (to enhance solution conductivity or varying the $\mathrm{pH}$ of the solution).

Calculation of operating cost for initial COD $52000 \mathrm{mg} / \mathrm{L}$.

$$
\text { Operating cost }=\mathrm{a} \times \mathrm{C}_{\text {energy }}+\mathrm{b} \times \mathrm{C}_{\text {electrode }}+\mathrm{c} \times \mathrm{C}_{\text {chemical }}
$$

In the present study electrode and chemical consumption is very low, so the main operating cost related to only energy consumption.

It was observed that the operating cost increased with the initial COD concentration. It was found that about 375 $\mathrm{Rs} / \mathrm{m}^{3}$ is required for the treatment of distillery spentwash containing initial COD concentration of $52000 \mathrm{mg} / \mathrm{L}$.

\section{Comparison with Chemical Coagulation}

Experiments were conducted to compare the COD removal efficiency of reverse osmosis rejected effluent by electrocoagulation and chemical coagulation techniques. The limitations of coagulation are generation of large amount of sludge and the total dissolved solids are further increased. Aluminum sulphate $\left(\mathrm{Al}_{2}\left(\mathrm{SO}_{4}\right)_{3} \cdot 18 \mathrm{H}_{2} \mathrm{O}\right)$ was used as the chemical coagulant. Different amounts of coagulant were added ( 1 to $5 \mathrm{~g}$ in $300 \mathrm{~mL}$ solution) to vary the coagulant dose. After coagulation the solution was kept for four hours for settling, after which the sediment was separated by filtration. The supernatant liquid was analyzed for COD and the results are shown in Fig. 3. It can be noticed that, the COD removal efficiency obtained by electrocoagulation is much higher as compared to chemical coagulation technique. The maximum COD of $22 \%$ was obtained at a pH of 7.2 with a coagulant dose of $5 \mathrm{~g} / 300 \mathrm{~mL}$ of sample.

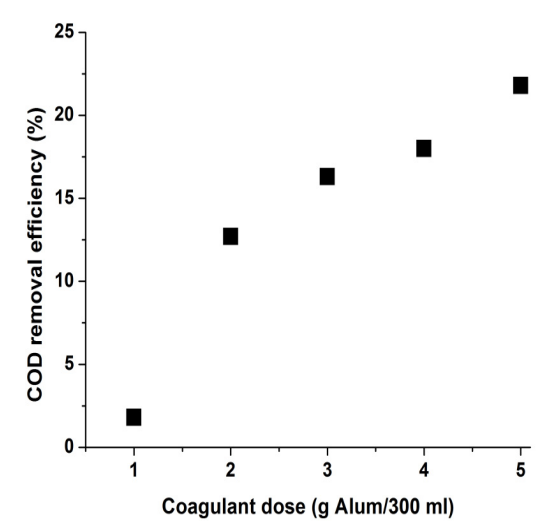

Fig. 3. Effect of coagulant dose on the COD removal efficiency, $\mathrm{pH} 7.2$, Settling time $4 \mathrm{hr}$, Initial COD $52000 \mathrm{mg} / \mathrm{L}$

\section{CONCLUSIONS}

The electrocoagulation of reverse osmosis rejected effluent of distillery was carried out using $\mathrm{Al}-\mathrm{Al}$ and $\mathrm{Fe}-\mathrm{Fe}$ electrodes in batch mode of operation and the optimum values of various operating parameters were obtained. The optimum value of current density was found to be $17.9 \mathrm{~mA} / \mathrm{cm}^{2}$ at initial $\mathrm{pH}$ of the solution 7.2. A $98 \% \mathrm{COD}$ removal efficiency was obtained at an electrolysis time of 3 $\mathrm{h}$ using $\mathrm{Al}-\mathrm{Al}$ electrode. It can be concluded that the electrocoagulaton technique can be successfully employed for the treatment of distillery effluent having high organic content.

\section{REFERENCES}

[1] M. S. Chauhan and A. K. Dikshit, "Indian distillery industry: problems and prospects of decolourisation of spentwash," in Proc. The International Conference on Future Environment and Energy (IPCBEE), Singapoore, 2012, pp. 119-123.

[2] V. Khandegar and A. K. Saroha, "Electrochemical treatment of distillery spent wash using aluminum and iron electrodes," Chinese Journal of Chemical Engineering, vol. 20, no. 3, pp. 439-443, 2012.

[3] Y. Satyawali and M. Balakrishnan, "Wastewater treatment in molasses-based alcohol distilleries for COD and color removal: A review," Journal of Environmental Management, vol. 86, no. 3, pp. 481-497, 2008.

[4] R. A. Pandey, A. Malhotra, S. Tankhiwale, S. Pande, P. P Pathe, and S. N. Kaul, "Treatment of biologically treated distillery effluent-a case study," International Journal of Environmental Study, vol. 60, pp. $263-275,2003$

[5] C. Thakur, V. C. Srivastava, and I. D. Mall, "Electrochemical treatment of a distillery wastewater: Parametric and residue disposal study," Chemical Engineering Journal, vol. 148, pp. 496-505, 2009.

[6] T. Sreethawong and S. Chavadej, "Color removal of distillery wastewater by ozonation in the absence and presence of immobilized iron oxide catalyst," Journal of Hazardous Material, vol. 155, pp. 486-493, 2008.

[7] B. M. Krishna, U. N. Murthy, B. M. Kumar, and K. S. Lokesh, "Electrochemical pretreatment of distillery wastewater using aluminum electrode," Journal of Applied Electrochemistry, vol. 40, pp. 663-667, 2010.

[8] M. Panizza, P. A. Michaud, G. Cerisola, and C. Comninellis, "Anodic oxidation of 2-Naphthol at boron doped diamond electrodes," Electroanal Chemistry, vol. 507W, pp. 206-213, 2001.

[9] N. N. Rao, K. M. Somasekhar, S. N. Kaul, and L. Szpyrkowicz, "Electrochemical oxidation of tannery," Journal of Chemical Technology and Biotechnology, vol. 76, pp. 1124-1131, 2001. 
[10] T. C. Wen, "Electro-deposited $\mathrm{PbO}_{2}$ Anode for the decomposition of low concentration of Cyanide," Plating and Surface Finishing, vol. 77, pp. 54-57, 1990.

[11] A. Akyol, "Treatment of paint manufacturing wastewater by electrocoagulation," Desalination, vol. 285, pp. 91-99, 2012.

[12] B. K. Korbahti, K. Artut, C. Geçgel, and A. Ozer, "Electrochemical decolorization of textile dyes and removal of metal ions from textile dye and metal ion binary mixtures," Chemical Engineering Journal, vol. 173, no. 3, pp. 677-688, 2011.

[13] P. Manisankar, C. Rani, and S. Viswanathan, "Effect of halides in the electrochemical treatment of distillery effluent," Chemosphere, vol. 57, pp. 961-966, 2004.

[14] R. K. Prasad and S. N. Srivastava, "Electrochemical degradation of distillery spent wash using catalytic anode: factorial design of experiments," Chemical Engineering Journal, vol. 146, pp. 22-29, 2009.

[15] S. K. Verma, V. Khandegar, and A. K. Saroha, "Removal of chromium from electroplating industry effluent using electrocoagulation," Journal of Hazardous Toxic and Radioactive Waste, vol. 17, no. 2, pp. 146-152, 2013.

[16] V. Khandegar, A. K. Saroha, "Electrochemical treatment of textile effluent containing Acid Red 131 dye," Journal of Hazardous Toxic and Radioactive Waste, (in press).

[17] APHA (American Public Health Association). (1998). Standard Methods for the Examination of Water and Wastewater. 20th Ed. Washington DC.
[18] N. Modirshahla, M. A. Behnajady, and S. Kooshaiian, "Investigation of the effect of different electrode connections on the removal efficiency of tartrazine from aqueous solutions by electrocoagulation," Dyes and Pigment, vol. 74, no.2, pp. 249-257, 2007.

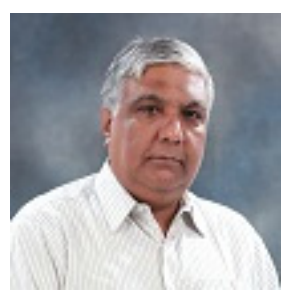

Anil K. Saroha received his Ph.D. and M.Tech. in Chemical Engineering from Indian Institute of Technology, Delhi (India). He is a professor in Dept. of Chemical Engineering, Indian Institute of Technology, Delhi (India). He is an honorary editor, Indian Chemical Enginee (Journal of Indian Institute of Chemical Engineers). His research interest is Multiphase Reactors and Environmental Engineering.

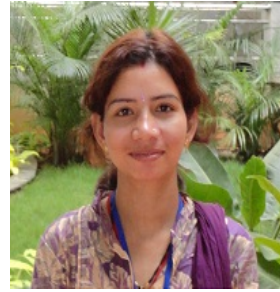

V. Khandegar received her M.Tech and B.E. in Chemical Engineering from Ujjain Engineering College Ujjain (India). She is Research Scholar in Chemical Engineering Dept., Indian Institute of Technology, Delhi (India). She worked as lecture in Dept. of Chemical Engineering, Institute of Engineering and Science, Indore (India). Her research interest is Environmental Engineering. 